\title{
4.5 Problems and prospects of online education in higher educational institutions
}

Distance learning involves the interaction of real subjects of education in a virtual environment using special means of communication. The specificity of the interaction environment and the peculiarities of the organization of educational information in the absence of direct contact between the student and the teacher determine the psychological and pedagogical features of distance learning.

This theme is very topical nowadays. And many scientists have already studied the topic: Berg, Gary, Stygalov Yu. M., Bayeva L. V. and many more. It brought lot's of challenges and opportunities. It proved to be ineffective when trying to apply the offline means of teaching to on-line education. Our goal is to derive the best and most productive ways of education.

Educational process is very versatile and thus needs to be seen from different positions:

1. Lecture;

2. Seminar;

3. Practise;

We can define some of the common disadvantages, brought by distance learning, and the main and most harmful is, of course, deprival of psychological connection between the teacher and the student, because of transparent wall of internet connection. Contingently we call it "a phone conversation" factor.

"A phone conversation" factor's idea lies upon the fact that people feel it easy to refuse when speaking on the phone rather than in private face to face conversation. It happens because of different perception.

When speaking about distance learning, we should take into account that it goes not only about technical means of rendering information. As the whole learning process is NOT about simply delivering some processed the most useful information. For this purpose we could use videos or audios. It goes, above of all, about perception. 
And the perception of material by the students, provided by a lecturer depends on how students perceive the lecturer. Because, the degree of a student's involvement into educational process depends on the authority of the teacher.

Though, "in many respects, the creation of electronic culture is a new type of creativity, it cannot be attributed only to the material or spiritual sphere, since it has features of both. Having created a "second nature" - the world of things, man, in fact, gave birth to a third nature - the world of virtual phenomena, which is a kind of synthesis of the world of consciousness and modern high information technologies. Just as the invention of the microscope or telescope opened up new worlds for researchers, the invention of IT technologies opened up a new life world for users, in which the problems of space, time, language, human restrictions on social status and physical parameters were largely removed" as states Bayeva Liudmila Vladimirovna.[253] The statement to our opinion is a very controversial one or at list to fold. The authority of the teacher is vitally important for learning process. As it involves such needed factors as: inspiration and aspiration. Which are largely ensue from the factor of authority.

The forced work of universities remotely in the context of the pandemic (COVID-19) has generated a lot of discussion about the benefits of the new form of education. The first results were summed up and reports were presented, the materials of which showed that the main goal of online education - the prevention of the spread of infection, - has been achieved. Against this background, proposals and publications have appeared substantiating the effectiveness of the massive introduction of distance learning, including in higher education. However, the assessment of such training by the population and students in publications and in social networks was predominantly negative and showed that the number of emerging problems exceeds the possible benefits of the new educational technology. Based on the analysis of the materials of publications and personal experience of teaching online, the potential benefits and problems of distance learning in higher education are considered. It is proposed to consider the effects separately for the suppliers of new technology (government, universities) and consumers (students, teachers, society). It is substantiated that the 
massive introduction of online education allows not only to reduce the negative consequences of epidemics, but also to reduce budgetary funding for universities, optimize the age composition of teachers, and reduce the cost of maintaining educational buildings. However, there will be a leveling / averaging of the quality of education, and responsibility for the quality of training will shift from the state/universities to students. The critical shortcomings of online education are the low degree of readiness of the digital infrastructure, the lack of a mechanism for identifying and monitoring the work of students, information security problems, and the lack of trust in such training of the population. The massive use of online education creates a number of risks for the country, the most critical of which is the destruction of the higher education system and a drop in the effectiveness of personnel training. The consequences of this risk realization are not compensated by any possible budget savings [254].

We can never underestimate the real need in increasing the literacy of population all over the globe, but to our opinion the most vicious thing that is about to happen is the dramatic downturn in the level of education if the approaches for distant education (that not deliberately turned out to be the today's reality for many teachers and students) will remain just the same.

According to the "livejournal" internet source the results of the poll shows that majority of people are against distant education and are for live communication in class education. The results of the poll, where 526 people were questioned about their attitude towards distant education, proved to be negative and are depicted in the figure № 1. given bellow. 


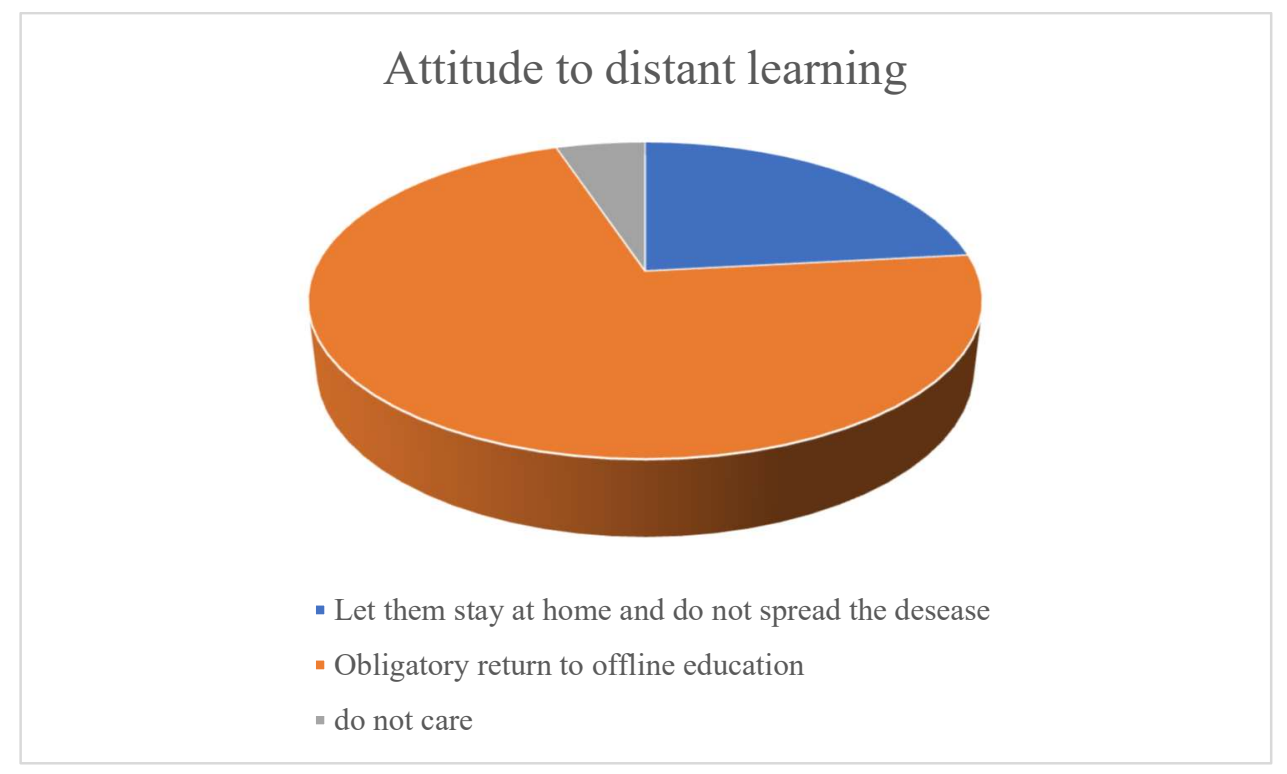

Figure 1. Attitude to distant learning.

$23,38 \%$ consider that distant education is acceptable under pandemic conditions. $71,86 \%$ think it is of vital importance to get back to normal in class education. $5,13 \%$ stayed indifferent.[258]

In accordance with another source, where 5000 people were asked, the results are approximately the same.

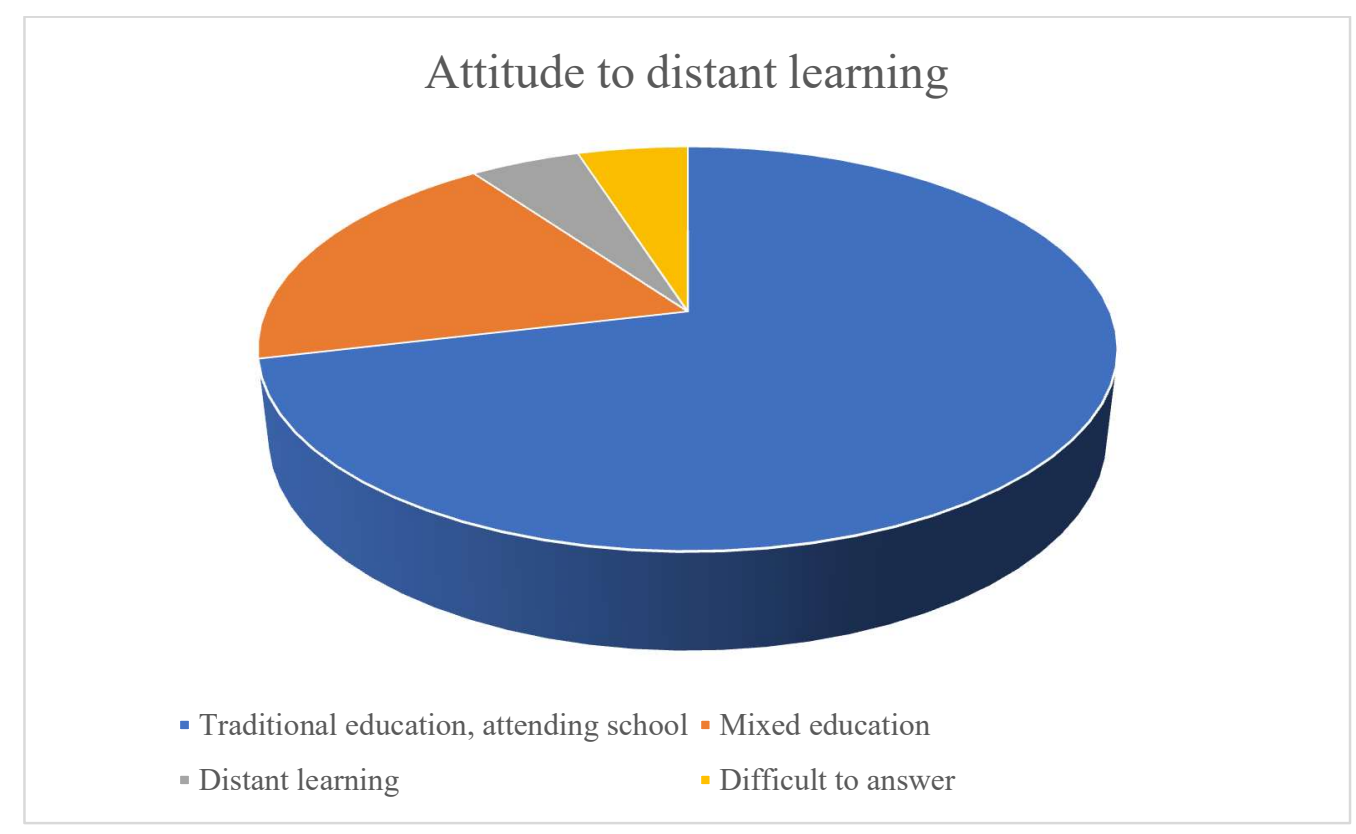

Figure 2. Attitude to distant learning.

Taking into account the data obtained within this poll we can conclude, that there is a clear understanding that traditional education is irreplaceable. 
$72 \%$ of people, who took part in the poll are sharply against distant learning. $19 \%$ consider it to be possible to accept mixed version of education. $5 \%$ have nothing against distant learning. 5\% consider it to be difficult to answer. [259]

The approaches that work for offline education (at least not all of them) are suitable and efficient for a distant form of education, to say nothing of those obsolete methods still used in the study rooms as those that are considered to belong to classical or old school methods. And the most ridiculous thing about what is happening in one of the most important spheres of human beings`activity is when advances technologies are being tried to be drown onto those methods to represent the ensuing transformation as a new and effective way of education. But the matter of fact is that the result of described above actions is some kind of disability.

We cannot escape mentioning some sort of discrimination that occurs against those participants of educational process, who simply do not possess corresponding equipment that would meet the requirement and be able to eliminate lags and going downs of the system.

According to the statistics given in electronic source "The correspondent" $68 \%$ of questioned people consider themselves to be poor. [259]

We cannot omit mentioning that education is not simply a process, but first of all, the process aimed to obtain measured results. So, if would be totally hypocritic to talk exclusively how convenient or inconvenient, affordable or difficult to afford this or that type of learning is. What is the most important and worth discussing is the result of common work for both the ones, who deliver education to students and from student.

In this respect we would like to present you another statistical data obtained by In accordance with the results of the polls, conducted by this source, where 5000 people were asked $66 \%$ people think the results of education worsened, and the knowledge obtained by students are poor; $18 \%$ think, that there in no difference in result between distant and off-line learning; 8\% HOPE for improvement. "Hope" is the key word that depicts how ridiculous is the situation, where for every participant of this process it is obvious that distant learning proved to be invalid.

Schematically you can see the result in the figure №3 bellow: 


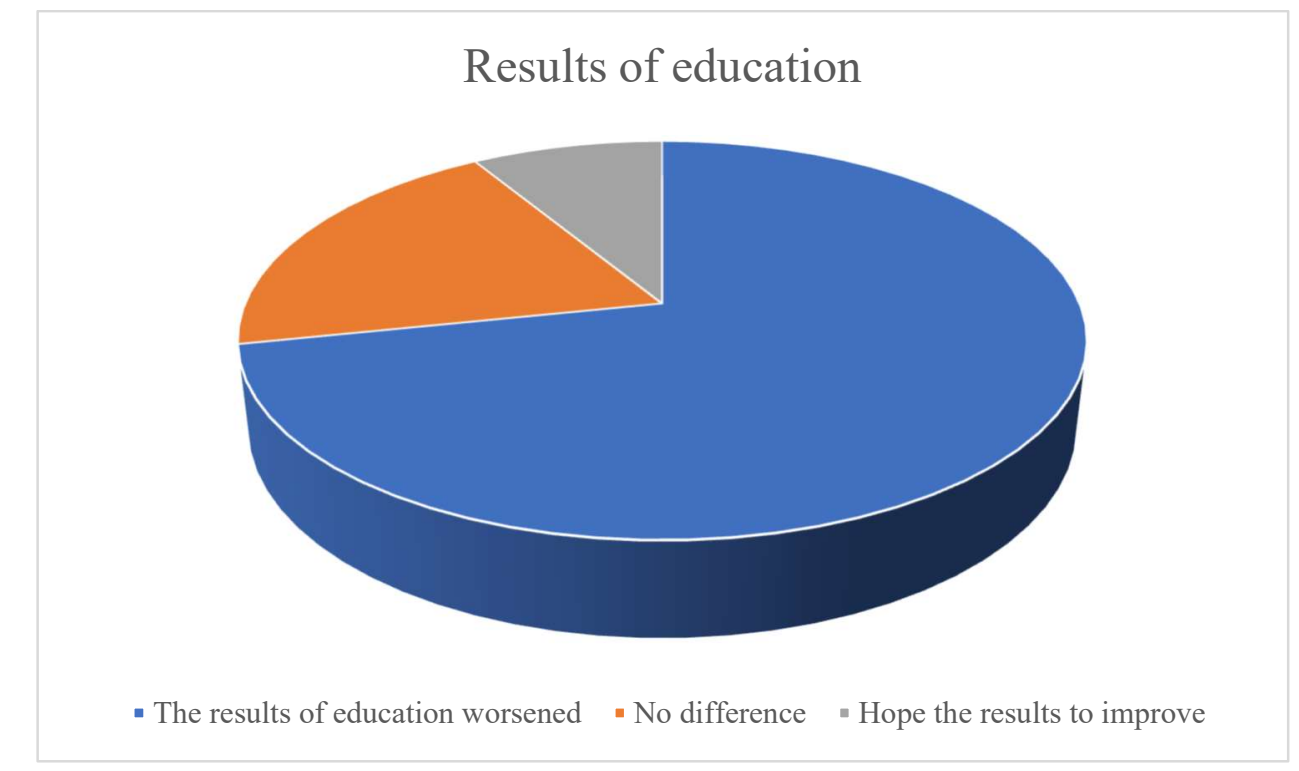

Figure 2. Results of distant learning.

Considering all this, we can summarize, that educational process under such conditions will give and already giving poor results in terms of residual students` knowledge.

All above said gives as the real picture of the state of affairs in the sphere of distant education as it is currently.

Among all the disadvantages of distance learning the most vicious and notorious is the tearing apart of the connection between the master (teacher) and the student. The authority, aspiration to knowledge and inspiration for achievement has been deprived from both sides through the depriving of that sacral connection. Which is a sly plan of making a whole generation of "people of one button".

Fortunately, those who realize what is going on find the way to restore the connection and adjust to the given conditions by changing the approach using the technologies for good and new methods of teaching are being developed, they take into account the experiences of the best result giving approaches and invent new ones.

And those are NOT tests! Tests cannot be used for teaching. Tests are one of the worst type of students ' check and cannot be represented as main form of revision. It deprived from students creativity skills and ability to express thought. Which can in not such a distant prospective give rise to ignorance and ignorance can give rise to destructions in all possible ways of its manifestations. 
In general, as shown by the results of an express survey of the Federal Institute for the Development of Education of the Russian Presidential Academy of National Economy and Public Administration, conducted at the beginning of the new academic year, about a third of students are pessimistic, panic, or indifferent about the upcoming study due to the threat of going to distant education.

The study involved 2,778 respondents from 38 constituent entities of the Russian Federation, $46 \%$ of the respondents clearly stated that they would like to study only in full-time format, since online education does not allow you to effectively engage in training [255]. 